\title{
SPECIFIC EFFECTS OF TEMPERATURE ON RECOMBINATION IN SCHIZOPHYLLUM COMMUNE
}

\author{
JUDITH STAMBERG and G. SIMCHEN \\ Biological Laboratories, Harvard University, Cambridge, Mass., U.S.A.; Department of Genetics, \\ University of Birmingham, England; and Laboratory of Genetics, * The Hebrew University, \\ Jerusalem, Israel
}

Received 2.iv.69

\section{INTRODUCTION}

THE effect of temperature on recombination frequency and chiasma formation has been investigated in numerous organisms, with notoriously inconsistent results. The first investigations were made by Plough (1917), who observed that Drosophila melanogaster females raised at 13 or $31^{\circ} \mathrm{C}$. had higher frequencies of crossing-over than those raised at $22^{\circ}$. The effect of temperature was not constant from one linkage group to another, however, or even from one region to another within a linkage group. The regions most sensitive to temperature were those near the centromeres. Lawrence (1963) found, however, that in crosses between inbred lines of Drosophila the effect of temperature was not confined to regions near the centromere.

The first report of a temperature effect on recombination in fungi was that of Hüttig (1931), who showed that in Ustilago hordei, studied at temperatures from 4 to $30^{\circ}$, the highest proportion of first-division segregation occurred at $8^{\circ}$. Olive (1956) studied recombination in Sordaria fimicola over a temperature range of $7-31^{\circ}$ and found that the temperature of maximum crossing-over was different for the three loci examined. Recombination in yeast was studied by Johnston and Mortimer (1967), who found that recombination in most regions did not vary from tempera ture to temperature; those regions that were affected by temperature had a lower frequency of recombination at the low temperature than at the high. Such regions were not always located near the centromeres.

The fungus in which the influence of temperature on recombination has been most fully studied is Neurospora crassa. Rifaat (1959) found that recombination in regions adjacent to the centromere increased with increasing temperatures, for the range $17-30^{\circ} \mathrm{C}$. Towe and Stadler (1964), however, reported that the frequency of crossing-over was higher at $18^{\circ}$ than at $25^{\circ}$. Regions close to the centromere exhibited a stronger response to temperature than did distal regions. Experiments of McNelly-Ingle, Lamb and Frost (1966) gave results compatible with those of Towe and Stadler: a U-shaped temperature-response curve, with the minimum recombination frequency at $25^{\circ}$. Nakamura (1966) found that the effect of temperature on crossingover differed not only for different chromosomes but even for the same chromosome region when tested in different crosses. Obviously, no clear understanding of the effect of temperature on recombination has yet emerged from these studies. Several workers (Rees and Thompson, 1958; Rifaat, 1959; McNelly-Ingle et al., 1966; Nakamura, 1966; Johnston and Mortimer,

* Present address of both authors. 
1967) have suggested that the temperature sensitivity of crossing-over is under genetic control; segregation of genetic factors could explain the heterogeneity observed.

In the fungus Schizophyllum commune mating competence is controlled by two unlinked factors, $A$ and $B$, each of which consists of two linked loci, $\alpha$ and $\beta$. Frequencies of recombination between the component loci of each factor were found to vary, for some crosses, at different temperatures (Raper, Baxter and Middleton, 1958; Stamberg, 1968). In the course of our studies on the genetic control of recombination in Schizophyllum, we found that the effects of temperature on recombination are highly region-specific. We have therefore been able to use temperature as a tool to distinguish various elements of the system controlling recombination.

\section{MAterials AND Methods}

The strains of $S$. commune originated from the collection of Professor J. R. Raper at Harvard University. Most were derived from isolates of this collection as segregants from crosses. The strains used are listed in table 1.

TABLE 1

Details of the main strains used

\begin{tabular}{|c|c|c|c|}
\hline Strain & Mating type & Other markers & Origin \\
\hline 14 & $A 4 B 4$ & & Harvard (fruit body from Ill.) \\
\hline 699 & $A 41 B 41$ & & Harvard (fruit body from Mass.) \\
\hline 5219 & $A 43 B 43$ & nic2-ura1- & Birmingham (derived) \\
\hline 991 & $A 97 B 97$ & & Harvard (fruit body from Costa Rica) \\
\hline MS-82 & $A 41 B 41$ & $\arg 7-$ & Harvard (derived) \\
\hline HS-55 & $A \alpha 1-\beta 6 B 41$ & $p a b-a d e 5-$ & Harvard (derived) \\
\hline $\mathrm{C} 40$ & $A 43 B 43$ & comp 2 pab- & Birmingham (derived) \\
\hline $\mathrm{C} 41$ & $A 43 B 43$ & comp2 pab- & Birmingham (derived) \\
\hline & $A 43 B 43$ & $x 15-$ & Birmingham (derived) \\
\hline
\end{tabular}

Abbreviations: nic $=$ nicotinic acid.

ura $=$ uracil.

$\arg =$ arginine.

$p a b=$ para-amino benzoic acid.

ade $=$ adenine.

comp $=$ " compact" morphology.

$x 15=$ unknown nutritional requirement.

Note: Linkage relationships are given by Simchen and Stamberg (1969a).

General procedures concerning fruiting, isolation of spores, and matingtype tests can be found in our previous publications (Simchen, 1967; Stamberg, 1968). With the exception of the experiment reported in section $3(a)$, in which time is a variable, crosses with sporulating fruiting bodies were incubated at the indicated meiotic temperature for at least 18 hours prior to the collection of spores for testing.

Strains were grown and crosses were performed on a complete medium (Koltin, Raper and Simchen, 1967); strains were scored for nutritional requirements on minimal or supplemented minimal medium (Raper and Miles, 1958). Morphological characteristics were scored macroscopically after several days' growth. 


\section{Results}

(a) Temperature response in the incompatibility factors

1. Time of response to a change in temperature. A dikaryon formed by strains $14 \times 699$ was maintained at $18^{\circ} \mathrm{C}$. until it was shedding spores profusely. A sample of spores was obtained (this was designated the time $=0$ sample) and the dikaryon was placed at $32^{\circ}$. Samples of from 100 to 350 spores were collected at various times up to 100 hours after the beginning of the incubation period; all were tested for recombination in the $A$ and $B$ factors (fig. 1).

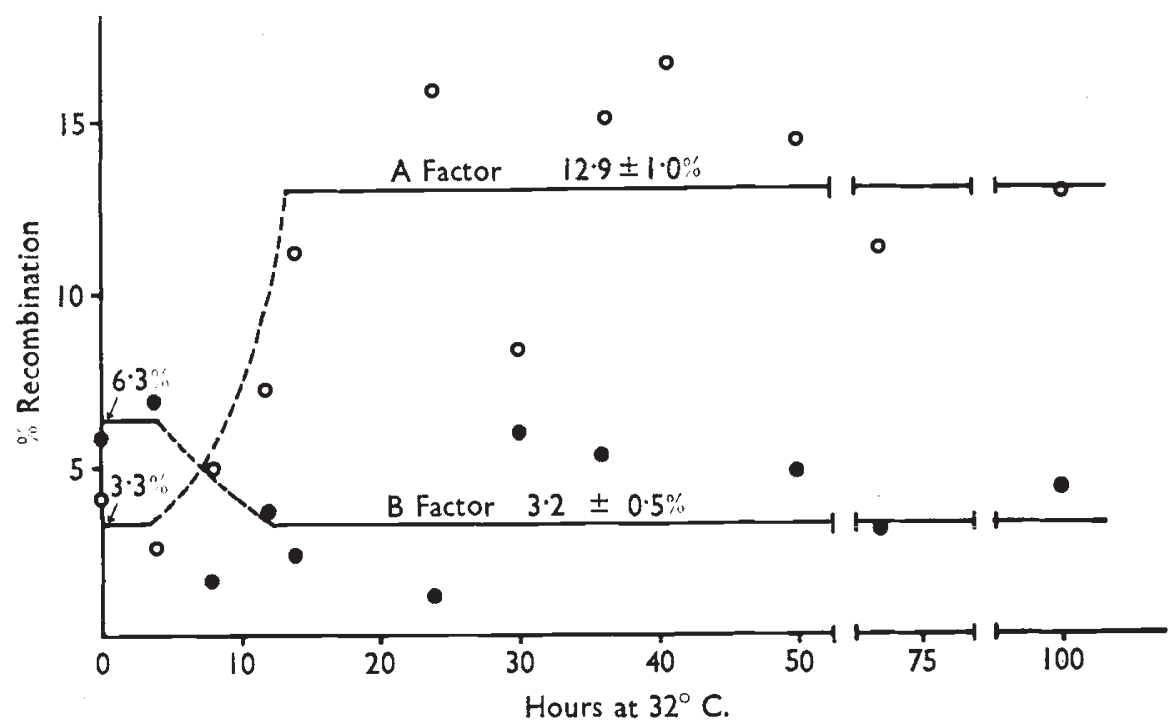

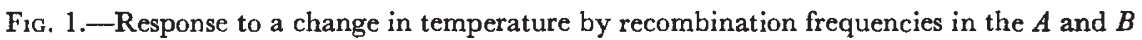
factors of dikaryon $14 \times 699$. The dikaryon was maintained at $18^{\circ}$ prior to the start of the timed experiment. At $t=0$ the dikaryon was placed at $32^{\circ}$. After 14 hours, frequencies of recombination were stabilised at the values indicated. Open circles represent frequencies of recombination in the $A$ factor; solid circles, frequencies of recombination in the $B$ factor.

Recombination frequencies in both the $A$ factor and the $B$ factor changed after incubation at $32^{\circ}$. The 0 -hour and 4 -hour values were obtained from spores that underwent meiosis at $18^{\circ}$; after 14 hours at $32^{\circ}$, the recombination frequencies were stabilised at new values that differed significantly from those at $18^{\circ}$ (for the $A$ factor, $\chi_{(1)}^{2}=27.0, \mathrm{P}<0.001$; for the $B$ factor, $\left.\chi_{(1)}^{2}=7.4, \mathrm{P}<0.01\right)$; the 8-hour and 12-hour values were intermediate, probably because the spores released then included some that had recombined at $18^{\circ}$ and some that had recombined later. That there was no change in recombination frequencies after 14 hours (for frequencies from 14 to 100 hours, $\chi_{(\theta)}^{2}=7 \cdot 6, \mathrm{P}>0.25$ for the $A$ factor; $\chi_{(\theta)}^{2}=8.2, \mathrm{P}>0.20$ for the $B$ factor) indicates that events occurring after recombination but before spore release occupy less than 14 hours.

2. Response to a range of temperatures. Replicate plates of the dikaryon formed by $14 \times 699$ were maintained at $18^{\circ}$ until they were shedding spores and were then placed at various temperatures for at least 36 hours before 
spores were collected. (Dikaryons were incubated at the appropriate temperatures longer than the minimum 14 hours in the expectation that meiosis at lower temperatures would be somewhat slower than at $32^{\circ}$. The

TABLE 2

Effect of temperature on recombination in the $\mathrm{A}$ and $\mathrm{B}$ factors of dikaryon $14 \times 699$

$\begin{array}{cccc}\text { Temperature }\left({ }^{\circ} \text { C. }\right) & \text { Sample } & \text { \% Rec. } A & \text { \% Rec. } B \\ 15 & 140 & 2 \cdot 1 & 7 \cdot 9 \\ 18 & 363 & 3 \cdot 3 & 6 \cdot 3 \\ 21 & 139 & 2 \cdot 2 & 10 \cdot 8 \\ 23 & 188 & 2 \cdot 1 & 8 \cdot 5 \\ 25 & 157 & 1 \cdot 9 & 7 \cdot 0 \\ 28 & 267 & 2 \cdot 6 & 9 \cdot 7 \\ 30 & 205 & 4 \cdot 9 & 2 \cdot 9 \\ 32 & 1224 & 12 \cdot 9 & 3 \cdot 2 \\ \chi_{(7)}^{2} \text { all temperatures } & 102 \cdot 6 * * * & 46 \cdot 0 * * * \\ \chi_{(6)}^{2} \text { for } 15^{\circ}-30^{\circ} & 5 \cdot 5 & \\ \chi_{(5)}^{2} \text { for } 15^{\circ}-28^{\circ} & & \\ \end{array}$

Significance levels in this and the following tables indicated as:

$$
\begin{array}{rl}
\text { unstarred: } & \mathrm{P}>0.05 \\
*: & \mathrm{P}=0.05-0.01 \\
* * & : \mathrm{P}=0.01-0.001 \\
* * * & \mathrm{P}<0.001
\end{array}
$$

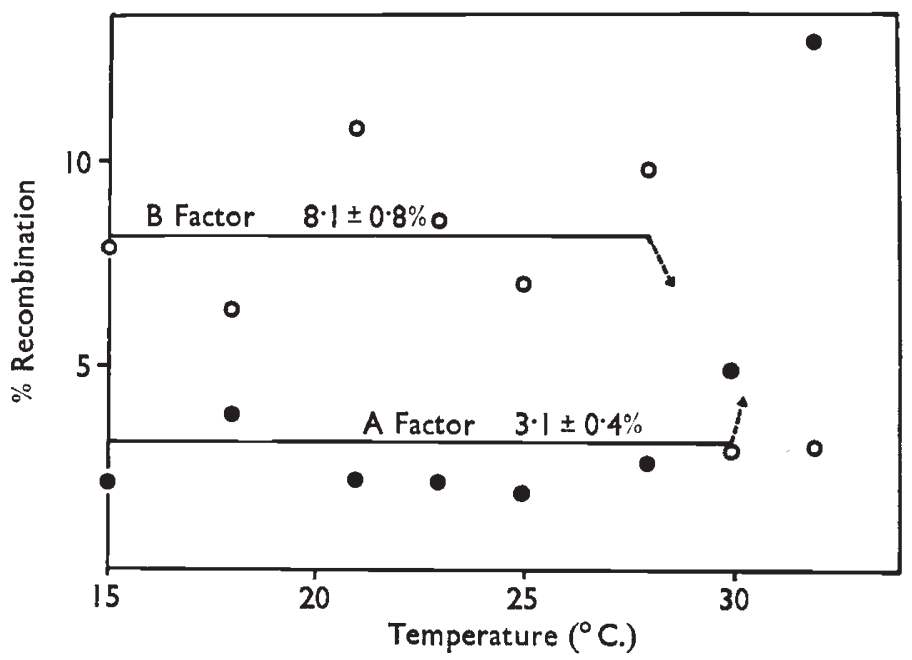

Fig. 2.-Temperature-response curve for recombination frequencies in the $A$ and $B$ factors of dikaryon $14 \times 699$. Recombination frequencies were constant between 15 and $30^{\circ}$ in the $A$ factor, and between 15 and $28^{\circ}$ in the $B$ factor. Solid circles represent frequencies of recombination in the $A$ factor; open circles, frequencies of recombination in the $B$ factor.

dikaryon placed at $15^{\circ}$ was maintained at this temperature for 120 hours prior to the collection of a spore sample. No spores were released from fruiting bodies at temperatures higher than $32^{\circ}$.) Results are given in table 2 and fig. 2. 
Recombination in the $A$ factor was constant and low from 15 to $30^{\circ}$, inclusive. An abrupt transition must occur between 30 and $32^{\circ}$, for at the latter temperature recombination was significantly more frequent than at the other temperatures. In the $B$ factor, the effect of temperature was the reverse. Recombination in this region was constant and high from 15 to $28^{\circ}$, inclusive. Between 28 and $30^{\circ}$ a transition occurs; at 30 and $32^{\circ}$ recombination was significantly less frequent than at the lower temperatures. The critical temperature is thus slightly different for recombination in the two regions.

\section{(b) Temperature response in a third linkage group.}

The genes nic2 and ural are linked to each other but unlinked to the $A$ or $B$ factor (Raper and Miles, 1958); the use of a strain carrying nic2 and ural thus made it possible to study recombination on three linkage groups simultaneously.

TABLE 3

Effect of temperature on recombination in three unlinked regions

\begin{tabular}{|c|c|c|c|c|c|c|c|c|c|c|c|}
\hline \multirow[b]{2}{*}{ Strain $\dagger$} & \multicolumn{2}{|c|}{ Sample } & \multicolumn{2}{|c|}{$\%$ Rec. $A$} & \multirow{2}{*}{$\begin{array}{c}\chi_{(1)}^{2} \text { for } \\
\text { tempera- } \\
\text { ture } \\
\text { variation }\end{array}$} & \multicolumn{2}{|c|}{$\%$ Rec. $B$} & \multirow{2}{*}{$\begin{array}{c}\chi_{(1)}^{2} \text { for } \\
\text { tempera- } \\
\text { ture } \\
\text { variation }\end{array}$} & \multicolumn{2}{|c|}{$\begin{array}{l}\% \text { Rec. } \\
\text { nic2-ura } 1\end{array}$} & \multirow{2}{*}{$\begin{array}{c}\chi_{(1)}^{2} \text { for } \\
\text { tempera- } \\
\text { ture } \\
\text { variation }\end{array}$} \\
\hline & $18^{\circ}$ & $32^{\circ}$ & $18^{\circ}$ & $32^{\circ}$ & & $18^{\circ}$ & $32^{\circ}$ & & $18^{\circ}$ & $32^{\circ}$ & \\
\hline Paren & & & & & & & & & & & \\
\hline & 182 & 179 & $3 \cdot 9$ & $11 \cdot 7$ & $7 \cdot 8 * *$ & $3 \cdot 9$ & $4 \cdot 5$ & $0 \cdot 1$ & $22 \cdot 5$ & $12 \cdot 3$ & $6 \cdot 6 *$ \\
\hline $\begin{array}{l}\text { Progeny } \\
\quad \text { of } \\
5219 \times\end{array}$ & & & & & & & & & & & \\
\hline 1 & 129 & 152 & $14 \cdot 0$ & $12 \cdot 5$ & $0 \cdot 1$ & $3 \cdot 9$ & $5 \cdot 3$ & $0 \cdot 3$ & $34 \cdot 9$ & $17 \cdot 1$ & $11.7 * * *$ \\
\hline ? & 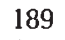 & 140 & 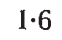 & $18 \cdot 6$ & $28.9 *$ & $9 \cdot 0$ & 2 . & $5 \cdot 5$ & $2 \cdot 8$ & 18 & 0.9 \\
\hline 3 & 1 & 174 & $1 \cdot 2$ & $14 \cdot 4$ & $20 \cdot 1 * * *$ & $4 \cdot 8$ & $2 \cdot 3$ & $1 \cdot 6$ & $25 \cdot 3$ & $19 \cdot 0$ & $2 \cdot 0$ \\
\hline 4 & & 186 & $4 \cdot 0$ & $9 \cdot 1$ & $3 \cdot \varepsilon$ & $3 \cdot 4$ & 0 . & $2 \cdot 6$ & 0 & $12 \cdot 9$ & 0.7 \\
\hline 5 & 174 & 140 & $2 \cdot 3$ & $12 \cdot 1$ & $12 \cdot 1 * * *$ & $4 \cdot 0$ & $5 \cdot 7$ & 0.5 & $15 \cdot 5$ & $22 \cdot 9$ & $2 \cdot 7$ \\
\hline
\end{tabular}

$\chi_{(4)}^{2}$ for genotype variation among progeny

$$
\begin{array}{llllll}
40 \cdot 0 * * * & 6 \cdot 6 & 7 \cdot 7 & 10 \cdot 6 * & 21 \cdot 4 * * * & 5 \cdot 8
\end{array}
$$

$\uparrow$ All strains were crossed $\times$ tester strain 14 .

The doubly auxotrophic strain 5219 was crossed to wild-type strain 699 . Five doubly auxotrophic progeny carrying the $A$ and $B$ factors of 699 were taken at random; these and the auxotrophic parent (5219) were crossed to tester strain 14. Recombination in the $A$ factor, the $B$ factor, and the nic2-ura1 region was measured after meiosis at both 18 and $32^{\circ}$ (table 3 ).

From the results at $18^{\circ}$ it has been previously concluded that recombination in the nic2-ural region is independent of that in the $B$ factor, for the former exhibited variation from genotype to genotype whereas recombination in the latter was constant (Simchen and Stamberg, 1969a). Furthermore, the pattern of response to the change in temperature, given here, shows that recombination in all three regions must vary independently of each other. Of the five progeny crosses, one varied only in nic2-ura1 recombination, two varied in recombination in the $A$ factor only, one varied 
in both the $A$ factor and the $B$ factor, and one showed no variation in any region, whereas the cross involving parent 5219 showed variation in both nic2-ura1 and $A$ factor recombination at the two temperatures. Thus, recombination in the $A$ factor may or may not vary from temperature to temperature; if it does vary it may be the only one of the three regions to do so, or it may vary at the same time as either the $B$ factor or the nic2-ural region.

\section{(c) Temperature response in regions linked to the incompatibility factors}

Markers linked to the incompatibility factors have been utilised to determine whether recombination throughout an entire linkage group is co-ordinately regulated. Although the linkage group on which the $B$ factor is located is not entirely satisfactory for the purpose (very few markers have been located on this linkage group and none is very close to the $B$ factor), nevertheless one marker was used; the results obtained support the conclusions reached from a study of regions linked to the $A$ factor.

TABLE 4

Effect of temperature on recombination in the $\mathrm{B}$ linkage group and in the $\mathrm{A}$ factor

\begin{tabular}{|c|c|c|c|c|c|c|c|c|c|c|c|}
\hline \multirow[b]{2}{*}{ train $\dagger$} & \multicolumn{2}{|c|}{ Sample } & \multicolumn{2}{|c|}{$\%$ Rec. $A$} & \multirow{2}{*}{$\begin{array}{l}\chi_{(1)}^{2} \text { for } \\
\text { tempera- } \\
\text { ture } \\
\text { variation }\end{array}$} & \multicolumn{2}{|c|}{$\%$ Rec. $B$} & \multirow{2}{*}{$\begin{array}{l}\chi_{(1)}^{2} \text { for } \\
\text { tempera- } \\
\text { ture } \\
\text { variation }\end{array}$} & \multicolumn{2}{|c|}{$\begin{array}{l}\text { \% Rec. } \\
\text { B-arg7 }\end{array}$} & \multirow{2}{*}{$\begin{array}{c}\chi_{(1)}^{2} \text { for } \\
\text { tempera- } \\
\text { ture } \\
\text { variation }\end{array}$} \\
\hline & $18^{\circ}$ & $32^{\circ}$ & $18^{\circ}$ & $32^{\circ}$ & & $18^{\circ}$ & $32^{\circ}$ & & $18^{\circ}$ & $32^{\circ}$ & \\
\hline 1 & & 140 & 5.0 & $9 \cdot 3$ & & 5.0 & 2 & 0 . & $29 \cdot 8$ & $48 \cdot 6$ & $11 \cdot 1^{*}$ \\
\hline & & & & & & & & & & & \\
\hline 3 & 172 & 173 & 1.7 & 20 & $30 \cdot 1^{*}$ & 6.4 & 1.7 & & $4 / 1$ & & \\
\hline 4 & 189 & 182 & 6.9 & 11.5 & 2.4 & 3.7 & $2 \cdot 2$ & 0.7 & 54.5 & $56 \cdot 6$ & 0.2 \\
\hline
\end{tabular}

+ The four strains were derived from a cross between MS-82 and 699. All had the genotype $A 41 B 41 \mathrm{arg}^{-}$and were crossed $\times$tester strain 14.

The $\arg 7$ marker has been reported to map about 38 units from the $B$ factor (Raper, 1966). Strain MS-82, carrying arg7, was crossed to strain 699 and four of the arg - progeny were taken at random and crossed to strain 14. Recombination frequencies in the $A$ factor, the $B$ factor, and the $B$-arg 7 region were assessed at 18 and $32^{\circ}$ (table 4 ). None of the four crosses varied in $B$ factor recombination at the two temperatures. Only one cross varied in the frequency of recombination between the $B$ factor and $\arg 7$ at the two temperatures; significantly, recombination within the $B$ factor did not vary simultaneously. Thus, the effect of temperature on recombination appears to be independent in the two linked regions. Because of the great distance between the $B$ factor and $\arg 7$, however, the frequency of double recombination in the region between them must be high; this would tend to obscure any correlation between recombination within the $B$ factor and that in a neighbouring region.

The linkage group on which the $A$ factor is located is well supplied with markers, several of which were used in studies to determine the extent of the region controlled jointly with the $A$ factor. Some of the data obtained in these studies have been reported elsewhere (Simchen and Stamberg, 1969a); here, however, we are concerned with the temperature effects that were revealed. 
The $x 15$ marker maps about 28 units from $A \beta$ (Ellingboe and Raper, 1962). Strain ES-1374, of genotype $A 43 B 43 \times 15^{-}$, was crossed to 699 and five progeny of genotype $A 41 B 41 \times 15^{-}$were taken at random, crossed to strain 14 and tested for frequencies of recombination at 18 and $32^{\circ}$ (table 5).

TABLE 5

Effect of temperature on recombination in the $A \beta-x 15$ region, the $\mathrm{A}$ factor, and the $\mathrm{B}$ factor

\begin{tabular}{|c|c|c|c|c|c|c|c|c|c|c|c|}
\hline \multirow[b]{2}{*}{ Strain $†$} & \multicolumn{2}{|c|}{$\overbrace{}^{\text {Sample }}$} & \multicolumn{2}{|c|}{$\%$ Rec. $A$} & \multirow{2}{*}{$\begin{array}{c}\chi_{(1)}^{2} \text { for } \\
\text { tempera- } \\
\text { ture } \\
\text { variation }\end{array}$} & \multicolumn{2}{|c|}{$\begin{array}{l}\% \text { Rec. } \\
A \beta-\times 15\end{array}$} & \multirow{2}{*}{$\begin{array}{c}\chi_{(1)}^{2} \text { for } \\
\text { tempera- } \\
\text { ture } \\
\text { variation }\end{array}$} & \multicolumn{2}{|c|}{$\%$ Rec $B$} & \multirow{2}{*}{$\begin{array}{l}\chi_{(1)}^{2} \text { for } \\
\text { tempera- } \\
\text { ture } \\
\text { variation }\end{array}$} \\
\hline & $18^{\circ}$ & $32^{\circ}$ & $18^{\circ}$ & $32^{\circ}$ & & $18^{\circ}$ & $32^{\circ}$ & & $18^{\circ}$ & $32^{\circ}$ & \\
\hline 1 & 192 & 200 & $1 \cdot 6$ & $3 \cdot 5$ & $1 \cdot 5$ & 43.8 & $35 \cdot 0$ & $3 \cdot 1$ & $3 \cdot 7$ & $3 \cdot 5$ & 0.0 \\
\hline 2 & 193 & 198 & $2 \cdot 6$ & $4 \cdot 6$ & $1 \cdot 1$ & $37 \cdot 3$ & $39 \cdot 4$ & $0 \cdot 2$ & $6 \cdot 7$ & $4 \cdot 6$ & 0.9 \\
\hline 3 & 193 & 194 & $2 \cdot 6$ & 8.8 & $6 \cdot 9 * *$ & 35.8 & $38 \cdot 7$ & 0.4 & $4 \cdot 7$ & $9 \cdot 3$ & $3 \cdot 2$ \\
\hline 4 & 197 & 172 & $1 \cdot 0$ & $11 \cdot 1$ & $17 \cdot 2 * * *$ & $29 \cdot 4$ & 34.9 & $1 \cdot 3$ & $3 \cdot 6$ & $2 \cdot 3$ & 0.5 \\
\hline 5 & 191 & 194 & $2 \cdot 1$ & 10.8 & $12 \cdot 1 * * *$ & 33.5 & $33 \cdot 0$ & 0.1 & $4 \cdot 2$ & $3 \cdot 1$ & 0.3 \\
\hline \multicolumn{12}{|c|}{${ }_{(4)}^{2}$ for genotype variation } \\
\hline & & & 1.9 & $13 \cdot 5$ & & $9 \cdot 4$ & $2 \cdot 5$ & & $3 \cdot 0$ & $3 \cdot$ & \\
\hline
\end{tabular}

$\dagger$ The five strains were derived from a cross between ES-1374 and 699. All had the genotype $A 41 B 41 \times 15^{-}$and were crossed $\times$tester strain 14 .

At $18^{\circ}$ there was no variation in recombination frequency in any of the three regions among the strains. At $32^{\circ}$, recombination in both the $A$ factor and the $B$ factor varied from genotype to genotype. There was, however, no correlation between frequencies in the two regions; the correlation coefficient $r$ is not significantly different from 0 . Recombination in the $A \beta-x 15$ region did not vary; this is one indication that recombination frequencies in these two adjacent regions are independent of each other (additional proof is given by Simchen and Stamberg, 1969a). A comparison of recombination frequencies at 18 and $32^{\circ}$ shows that, in three of the five crosses, recombination in the $A$ factor was affected by the change in temperature while in the other two crosses there was no change in $A$ factor recombination; but in all five crosses recombination between $A \beta$ and $x 15$ was unaffected by the temperature change. Thus, temperature may or may not affect $A$ factor recombination, depending on the genotype; but recombination in the adjacent $A \beta-x 15$ region is not simultaneously affected in these crosses.

Two markers, $p a b$ and ade5, map between the component loci of the $A$ factor (Raper, 1966). Wild-type strain 14, and four progeny of a cross between 14 and 699, were crossed to the doubly auxotrophic strain HS-55. Each cross was tested for recombination frequencies at low $\left(23^{\circ}\right)$ and high $\left(32^{\circ}\right)$ meiotic temperatures (table 6 ). In each of the six crosses recombination in the pab-ade 5 region varied at the two temperatures; in no cross was there variation in recombination in the ade5- $A \beta$ region; in only one cross was there significant temperature-induced variation in the $A \alpha-p a b$ region (although larger samples might well have revealed such variation in several other crosses, whose $\chi^{2}$ values approached significance). Thus, temperature affects recombination primarily in the $p a b$-ade 5 region and sometimes between $A \alpha$ and $p a b$ as well, without affecting recombination noticeably in the ade $5-A \beta$ region. From an analysis of the frequencies of recombination in the various subregions of the $A$ factor at $32^{\circ}$, Simchen and Stamberg (1969a) concluded that genotype variation in recombination occurred in the $A \alpha-p a b$ 


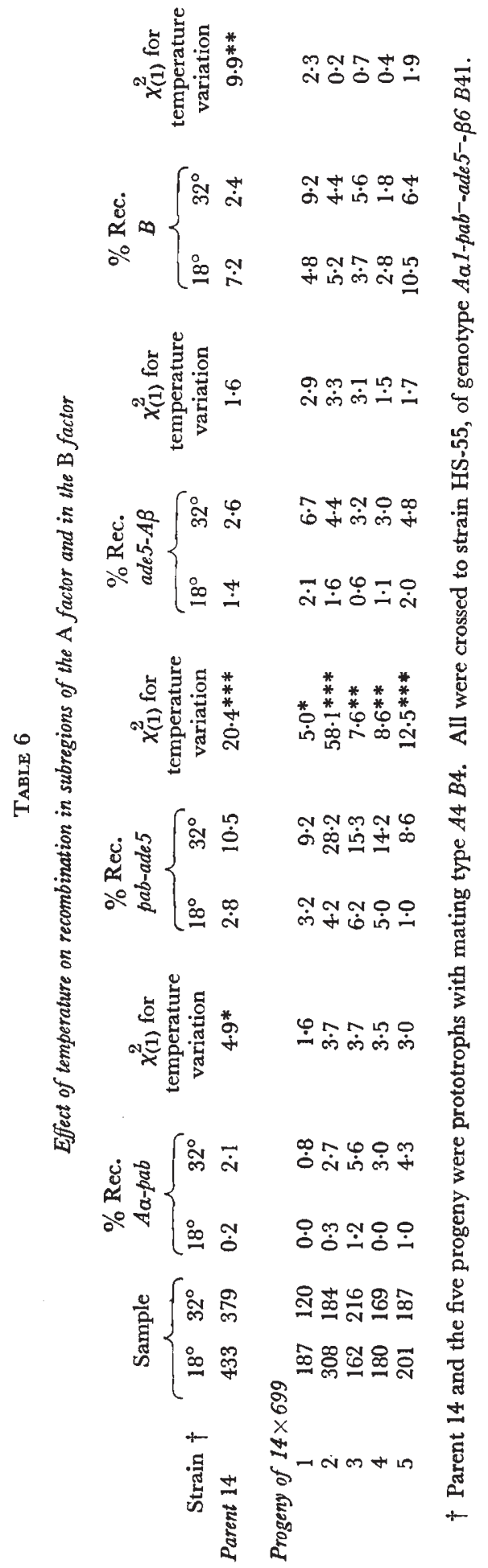


and pab-ade 5 regions, and that such variation was not due to a common gene-control. They found no evidence for genetic control of recombination in the ade $5-A \beta$ region. The pattern of temperature variation displayed here supports these conclusions.

The comp2 marker is located near the $A \alpha$ locus (Simchen and Stamberg, 1969a). Five crosses between sibling strains C40 and C41, both of genotype $A 43 B 43$ comp2 $p a b^{-}$, and three wild-type strains were tested for recombination frequencies at low and high meiotic temperatures (table 7). Of the five crosses, one varied in recombination at the two temperatures in the three linked regions, three varied in recombination in the comp2- $A \alpha$ and $p a b-A \beta$ regions but had no significant change in recombination in the $A \alpha-p a b$ region; and one cross varied only in the $p a b-A \beta$ region. In other words, the $p a b-A \beta$ region can vary in recombination from temperature to temperature while recombination in the other two regions is constant; it can vary along with the comp $2-A \alpha$ region; or all three regions can vary. In addition, the three linked regions do not exhibit genotypic variation at the same temperature: at $32^{\circ}$

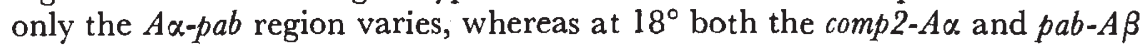
regions do so. Variation with respect to temperature (as well as to genotype, as shown by Simchen and Stamberg, 1969a), then, is independent in the three regions.

\section{Discussion}

In previous publications (Simchen, 1967; Simchen and Connolly, 1968; Stamberg, 1968; Simchen and Stamberg, 1969a) we have shown that recombination in Schizophyllum is under genetic control, and that recombination frequencies in adjacent chromosomal segments, as well as in unlinked segments, are independent of each other. The genes which individually affect recombination in specific, short segments, but which collectively control recombination throughout the genome have been termed the "fine control" of recombination (Stamberg, 1968; Simchen and Stamberg, $1969 b)$. The data presented in the preceding sections support our conclusion that the genes comprising the fine control are highly region-specific. A change in temperature generally does not affect frequencies of recombination in all marked segments of the genome. In our experiments involving three unlinked regions (table 3) we found a temperature effect in none, one, or two of the regions, depending on the genotypes of the strains. Similarly, adjacent regions were not always co-ordinately affected by a change in temperature (e.g., cross 1 , table 4 ; crosses $3,4,5$, table 5 ; all crosses, table 6 ; crosses 1, 2, 3, table 7). Furthermore, the temperature-response curves need not be identical for recombination in any two regions. For the two regions investigated at a range of temperatures, it was found that in one region recombination was constant until some point between 30 and $32^{\circ}$, whereas in the other region the frequency of recombination changed between 28 and $30^{\circ}$. The direction of change is also different in different regions; in some crosses, one region increased in recombination frequency, one region decreased, and one region was constant in response to an increase in temperature (e.g., cross 2, table 3; the parental cross, table 6).

It is our belief that the complexity of the effect of temperature on recombination is a direct reflection of the complexity of the fine control of recombination. Gene products made by different loci comprising the fine control may well have different sensitivities to temperature; this would 


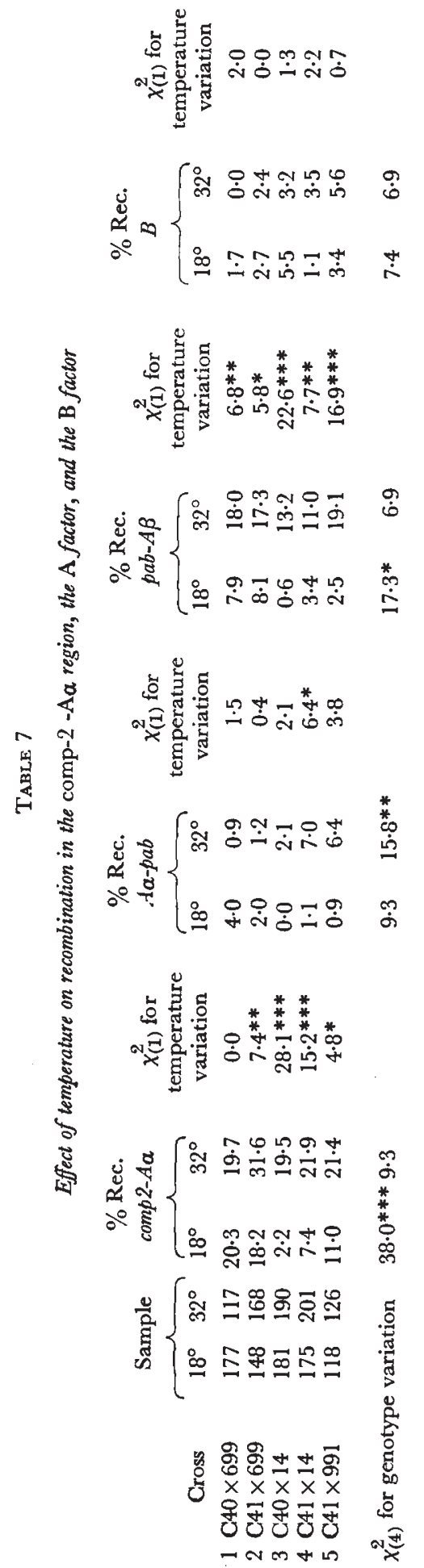


result in different effects of temperature on recombination in various regions within one genome. Likewise, gene products made by alternate alleles at one fine-control locus may also have different temperature sensitivities, resulting in different effects of temperature on recombination within one region in various crosses. Both kinds of variation have been found in Schizophyllum, and in other organisms as well (see Introduction).

Thus, the still widely-held beliefs (in spite of the accumulating evidence to the contrary) that effects of temperature are confined to regions near the centromeres, or are constant throughout the genome, or that temperatureresponse curves are always U-shaped, are erroneous. It is a serious oversimplification to generalise from the effect of temperature on recombination in one region, or in one cross, to the effect of temperature on recombination in other regions, or in other crosses. Although this complexity may be a nuisance to geneticists, we believe it has a great adaptive advantage to the organisms in which it occurs: new environmental conditions, such as changes in temperature, can release genetic variability at different rates for different regions of the genome, thus allowing each region to produce that amount of variation that will be optimal for the species.

\section{Summary}

1. The effect of temperature on recombination in adjacent and nonadjacent chromosomal regions has been studied in Schizophyllum commune.

2. A change in temperature need not affect frequencies of recombination throughout the genome; neither linked nor unlinked segments always respond co-ordinately to temperature.

3. The effect of temperature on recombination in any particular region can vary from cross to cross.

4. The effect of temperature on recombination is thus both regionspecific and genotype-specific. We believe this specificity is a manifestation of the complex "fine control" of recombination and has adaptive significance.

Acknowledgments.-We thank Miss Judy Hay for excellent technical assistance. The study was financed by a Public Health Service fellowship from the U.S. National Institutes of Health to the senior author.

\section{REFERENCES}

EllingBoe, A. H., AND RAPER, J. R. 1962. Somatic recombination in Schizophyllum commune. Genetics, 47, 85-98.

HütriG, w. 1931. Uber den Einfluss der Temperatur auf der Keimung und Geschlechtsverteilung bei Brandpilzen. Z. Bot., 24, 539-577.

JOHNSTON, J. R., AND MORTIMER, R. 1967. Influence of temperature on recombination in yeast. Heredity, 22, 297-303.

KOLTIN, Y., RAPER, J. R., AND SIMCHEN, G. 1967. The genetic structure of the incompatibility factors of Schizophyllum commune: the B factor. Proc. Natl. Acad. Sci., U.S., 57, 55-62.

LAWRENCE, M. J. 1963. The control of crossing-over in the X-chromosome of Drosophila melanogaster. Heredity, 18, 27-46.

MCNELLY-INGLE, C. A., LAMB, B. C., AND FROST, L. C. 1966. The effect of temperature on recombination frequency in Neurospora crassa. Genet. Res., Camb., 7, 169-183.

NAKAMURA, K. 1966. Heterogeneity in crossing-over frequency in Neurospora. Genetica, 37, 235-246.

olive, L. I. 1956. Genetics of Sordaria fimicola. I. Ascospore color mutants. Amer. J. Bot., $43,97-107$. 
PLOUGH, н. н. 1917. The effect of temperature on crossing-over in Drosophila. 7. Exp. Zool., $24,147-209$.

RAPER, J. R. 1966. Genetics of Sexuality in Higher Fungi. Ronald Press, New York. viii +283 pp. RAPER, J. R., BAXTER, M. G., AND MIDDLETON, R. B. 1958. The genetic structure of the incompatibility factors in Schizophyllum commune. Proc. Natl. Acad. Sci., U.S., 44, 889-900. RAPER, J. R., AND miles, P. G. 1958. The genetics of Schizophyllum commune. Genetics, 43, $530-546$.

REES, H., AND thompson, J. в. 1958. Genotypic control of chromosome behaviour in rye. V. The distribution pattern of chiasmata between pollen mother celis. Heredity, 12, $101-111$.

RifaAt, O. M. 1959. Effect of temperature on crossing-over in Neurospora crassa. Genetica, 30, 312-323.

sIMCHEN, G. 1967. Genetic control of recombination and the incompatibility system in Schizophyllum commune. Genet. Res., Camb., 9, 195-210.

sIMCHEN, G., AND CONNOlly, v. 1968. Changes in recombination frequency following inbreeding in Schizophyllum. Genetics, 58, 319-326.

simchen, G., AND STAMBERG, J. 1969a. Genetic control of recombination in Schizophyllum commune: Specific and independent regulation of adjacent and non-adjacent chromosomal regions. Heredity, 24, 369-381.

STMCHEN, G., AND STAMBERG, J. 1969b. Fine and coarse controls of genetic recombination, Nature, 222, 329-332.

STAMBERG, J. 1968. Two independent gene systems controlling recombination in Schizophyllum commune. Molec. Gen. Genetics, 102, 221-228.

TOWE, A. M., AND STADLER, D. R. 1964. Effects of temperature on crossing over in Neurospora. Genetics, 49, 577-583. 